\title{
Allelopathic effects of aqueous extracts of Avena fatua on seed germination and seedling growth of Triticum aestivum (variety GW-273).
}

\author{
Waseem Ahmad*, Muzafar Akbar, Umer Farooq, Aparna Alia, Fatima Khan. \\ Department of Botany Rajeev Gandhi College Bhopal (M.P) \\ Department of Botany Govt. Benazir College Bhopal (M.P)
}

\begin{abstract}
Wheat is an edible grain, one of the oldest and most important of the cereal crops. Though grown under a wide range of climates and soils, wheat is best adapted to temperate regions with rainfall between 30 and $90 \mathrm{~cm}$. Winter and spring wheat varieties are the two major types of the crop, with the severity of the winter determining whether a winter or spring type is cultivated. Avena fatua is a wildly growing weed along with wheat and is a serious competitor (competition in terms of allelochemicals) of wheat. Whole plants of Avena fatua were collected and dried, crushed, mixed with distilled water and allowed to stand for 72 hours in water bath at $25( \pm 2)$ degrees followed by filtration using whatman's filter paper no.1. Four concentrations of different ratios were prepared for demonstration of the allelopathic effects on wheat (GW-273) seed germination. The extracts pose significant and varying allelopathic effects on seed germination and other seedling growth parameters.
\end{abstract}

Key words: Allelopathic effects, GW 273, Avena fatua, Allelochemicals.

\section{Introduction:}

The term allelopathy, was introduced by Molisch in 1937, and is derived from two separate Greek words. They are allelon which means "of each other", and pathos which means "to suffer". Allelopathy refers to the beneficial or harmful effects of one plant on another plant; both crop and weed species, by the release of chemicals from plant parts by leaching, root exudation, volatilization, residue decomposition and other processes in both natural and agricultural systems. Chemicals with Allelopathic potential are present in a variety of plant tissues, including leaves, flowers, fruits, stems, roots, rhizomes, and seeds (Putnam, 1987). Weeds cause annual losses of about $10 \%$ in agricultural production (Anderson, 1987). Some weed species supplement aggressiveness by production of phytotoxic or plant growth inhibiting substances that adversely affect growth and development of other plants. These chemicals are released into the soil as root exudates of the living or dead plants (Ghafoor and Sadiq, 1991; Retta et al., 1991). Weeds compete for light, nutrients, moisture and space with the crop and thus cause severe losses to yield. Losses in wheat due to weeds range 17-25\% and in monetary terms it may be as high as Rs.28 billions (Hassan and Marwat, 2001).

Wheat (Triticum aestivum, family poaceae) GW-273 is grown as a winter wheat variety and is suitable for the agro-climatic conditions of Central India. Today, wheat is grown on more land area than any other commercial crop and continues to be the most important food grain source for humans (Sazada et al., 2009). Avena fatua belong to the Poaceae family along with wheat (Triticum aestivum), barley (Hordeum vulgare). Avena fatua is one of the most competitive grass weeds and is near equal competitors with wheat. Competition with the crop begins soon after emergence with most of the yield loss occurring in the first 6 weeks. It has been estimated that an infestation as small as 20 plants $\mathrm{m}^{-2}$ can cause a yield loss of $10 \%$ in a wheat crop yielding $2 \mathrm{t}$ $\mathrm{ha}^{-1}$ (Anderson 2003).

\section{Collection and Identification:}

\section{Materials and Methods:}

The wheat variety GW-273 is a certified variety, suitable for the agronomic conditions of Central India comprising of Bundelkhand, Rajasthan, Madhya Pradesh. The seeds were collected from the seed station situated in Powarkheda Hoshangabad (Madhya Pradesh).

Mature plants of Avena fatua were collected from the locally growing wheat fields during the month of January and first week of February care was taken that the plants having root system intact were selected. The plants were identified by using the expert opinion method and were also stored in the herbarium.

\section{Drying of plant material:}

Whole plants of Avena fatua were collected then washed with tap water 4-5 times to drench away the soil particles which were adhered on the lower parts of the plant, the plants were first shade dried for some days. 
Later the plants were cut into small pieces and dried in the oven at 80 degrees for 24 hours then crushed into powdered form with morter and pestle.

\section{Preparation of the treatment extracts:}

The dried plant material of Avena fatua was manually crushed and then were allowed to stand in double distilled water for 72 hours in the ratio of 1:10, 1:20, 1:30, 1:40 by w/v, (Avena fatua: Disttilled water) at a temperature of $25( \pm) 2$ degrees in a water bath.

After this the filtration process was carried out by first filtering the extract through a double layer of muslin cloth, and later on followed by filtration through Whatman's filter paper No.1.

\section{Seed germination bioassay:}

For seed germination bioassay seeds were selected on the basis of uniformity while all undersized and damaged seeds were discarded. Seed viability test was performed on the seeds used for bioassaying. The number of treatments were 5 (T1-T5: T1 represents the control and rest the different aqueous concentrations of Avena fatua) consisting of 3 replicates per treatment. Each replicate constituted of 10 seeds. The seeds were sterilized with $0.1 \%$ mercuric chloride solution then thoroughly washed with tap water and 3 times by distilled water to remove impurities if any prior to the treatment and were used for allelopathic studies. Bioassay constituted of germinating 10 seeds of Triticum aestivum (wheat) variety GW-273 in petridishes lined with double layer of Whatman's filter paper No.1. $10 \mathrm{ml}$ of each of the treatments (T1-T5) extract was applied in each plate. The bioassay was terminated after 10 days. The seed germination percentage, root and shoot length and root/shoot ratio was measured on the $10^{\text {th }}$ day.

\section{Results:}

From the results observed (mean \pm stdev) it is clear that, the aqueous whole plant extracts of Avena fatua showed highly reduced seed germination, root length, shoot length and root/shoot ratios as compared to the control. The calculations were interpreted statistically by using one-way ANOVA applying Bonoferonni (t-test) for pairwise multiple comparisons.

\section{Effect on seed germination percentage:}

Seed germination is defined as the emergence and development, from the seed embryo, of essential structures, which are capable of producing a normal plant under favorable conditions (Howell 1960). According to Musik (1970), germination is the period during which physiological processes are initiated in seed, leading to the elongation of cells, formation of new cells, tissues and organs thus it represents the period between hydration and onset of meristematic activity. Analysis of the data revealed that different plant (Avena fatua) water extracts significantly $(\mathrm{P}<0.001)$ affected germination percentage of wheat (Triticum aestivum) variety GW-273. Maximum (80.000 \pm 0.407$)$ seed germination was observed in control while the minimum was observed in T2 $(33.333 \pm 0.479)$ and it was significantly $(\mathrm{P}<0.001)$ lower than all other treatment concentrations. Germination percentage at the concentration ranges of $1: 40,1: 30$, and $1: 20$ was $(50.000 \pm 0.509),(53.333 \pm 0.507)$ and $(56.667 \pm 0.504)$ respectively.

\section{Effect on root length:}

Statistical analysis of the data showed that the different plant (Avena fatua) water extracts significantly $(\mathrm{P}<0.001)$ affected the root length of GW-273 wheat (triticum aestivum) variety. T2 expressed the most inhibiting factor in root length $(4.340 \pm 1.712 \mathrm{~cm})$ followed by T3 $(8.676 \pm 2.452 \mathrm{~cm})$ and these were significantly $(\mathrm{P}<0.001)$ lower than all other treatments. As stated by Rice $(1984)$ certain allelochemicals may inhibit the growth of specie at a particular concentration the same may stimulate the growth of the same species at other concentration as it was evident from the data, treatment T5 showed a stimulating effect in shoot length $(12.367 \pm 3.009 \mathrm{~cm})$ over control $(11.383 \pm 3.297)$ while the treatment concentration $\mathrm{T} 4$ has nearly equivalent value as of control (11.625 \pm 2.668$)$. Multiple comparison in between groups also showed that there is a statistically non-significant difference in between treatment groups of (1:40/control, 1:40/1:30, 1:30/control) when compared with each other. Hence it can be concluded that on variation of concentration of test sample significantly variable changes in root length was observed.

\section{Effect on shoot length:}

Statistical analysis of the data exhibited that the different plant (Avena fatua) water extracts significantly $(\mathrm{P}<0.001)$ affected the shoot length of wheat (Triticum aestivum) variety GW-273. Maximum shoot length $(14.653 \pm 1.741 \mathrm{~cm})$ was recorded for seeds receiving distilled water it was significantly $(\mathrm{P}<0.001)$ higher than all other treatments. While the minimum $(4.560 \pm 1.524 \mathrm{~cm})$ shoot length was observed in $\mathrm{T} 2(1: 10)$ and it was significantly $(\mathrm{P}<0.001)$ less than the other treatment concentrations. Shoot lengths at concentration ranges 
of $1: 40,1: 30,1: 20$ was $(14.353 \pm 1.731 \mathrm{~cm}),(12.794 \pm 1.759 \mathrm{~cm})$ and $(9.794 \pm 2.853 \mathrm{~cm})$ respectively. Multiple comparison in between groups showed that there is a statistically non-significant difference in between treatment groups (control/ 1:40) when compared with each other.

\section{Effect on root/shoot ratio:}

This parameter is an indicator of relative growth in root and shoot of a plant; the data revealed that there is a substantial variation in root and shoot lengths among the various treatment concentrations. Root shoot

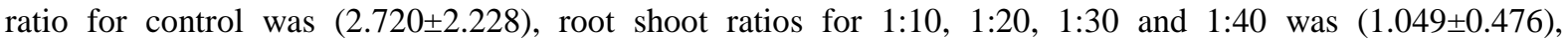
(0.968 \pm 0.418$),(0.908 \pm 0.171)$ and $(0.849 \pm 0.212)$ respectively. Multiple comparison in between groups also showed that there is a statistically non-significant difference in between treatment groups $(1: 10 / 1: 40,1: 10 / 1: 20$, 1:10/1:30, 1:20/1:40, 1:20/1:40) when compared with each other.

\section{Discussion:}

Allelochemicals are considered as either seed germination regulators or inhibitors (Murray et al., 1982). Seed is an ideal tool because it is dispersal of life formed by three parts that are genetically different. It contains seed coat, endosperm and an embryo able to support out in a new plant if exposed to the right conditions (Evenari 1980). The critical stage in the establishment of a plant is the seed germination. For successful establishment, the germination percentage should be high, the germination requirement should be minimal, the sensitivity of germinating seeds to the environment factors should be low and the process of germination should be quick (Kaul and Mangal, 1985a, 1987b).

The study demonstrated that aqueous extracts of Avena fatua exhibit significant inhibitory effects on all parameters evaluated due to phytotoxic and allelopathic interactions on Triticum aestivum cultivar GW-273. The seed germination percentage of the tested seeds was measured to be less than that of control (T1) at all the concentrations (T2-T5) of Avena fatua extract. The degree of inhibition increases with increase in extract concentration, all concentrations inhibited the seed germination, exhibiting a strong reciprocal correlation showing a dose response relationship. Along with percent reduction in seed germination, delay in onset of seed germination was also witnessed in various treatment categories. Maximum seed survival percentage was recorded in control, most affected treatment category is T2 (1:10) in which net germination percentage was reduced, followed by T5 (1:40) while minimum inhibition was witnessed in treatment concentrations of T3 and $\mathrm{T} 4$ respectively. In addition to germination even the subsequent seedling growth and development was also hampered. Seedling parameters like root length, shoot length and root-shoot ratio were found drastically affected especially in T2 (1:10) and T5 (1:40) treatment categories. Thus the present study has demonstrated the fact that aqueous extracts from Avena fatua weed exhibited allelopathic activity, which depended on the concentration levels. This is in agreement with many well documented reports. Nielsen et al. (1960) reported in vitro toxicity of water extracts of dry straw of Avena sativa, a species closely related to Avena fatua. This was also supported by the work of Guenzi and Mc Calla (1962) who reported inhibition of wheat growth from Avena sativa water extracts. Guenzi and Mc Calla, (1966) demonstrated the presence of five phenolic acids in the straw of Avena sativa such as ferulic, p-hydroxybenzoic, syringic and vanillic acids. These compounds were found to significantly inhibit the growth of wheat seedlings. Similarly, Schumacher et al. (1983) reported the presence of coumaric acid and vanillic acid in root exudates of wild oats (Avena fatua) which were reported to reduce the growth of wheat shoots.

The seed germination and seedling growth of pearl millet, turnip, corn, wheat, carrot and mustard were inhibited by aqueous extract of Anagallis arvensis (Zenab et al., 2001). In competition with Chenopodium album for potassium (K), 25.59\% reduction in grain yield of wheat was observed by Tanveer et al., (2001). Schumacher et al., (1982) found that water extracts from 23 common weed and crop species inhibited germination and growth of wheat seedlings. Similarly Bhatia et al., (1982) studied the allelopathic effects of some weeds on wheat. Chenopodium album L. and amaranthus viridis L. inhibited the growth of wheat seedlings. 


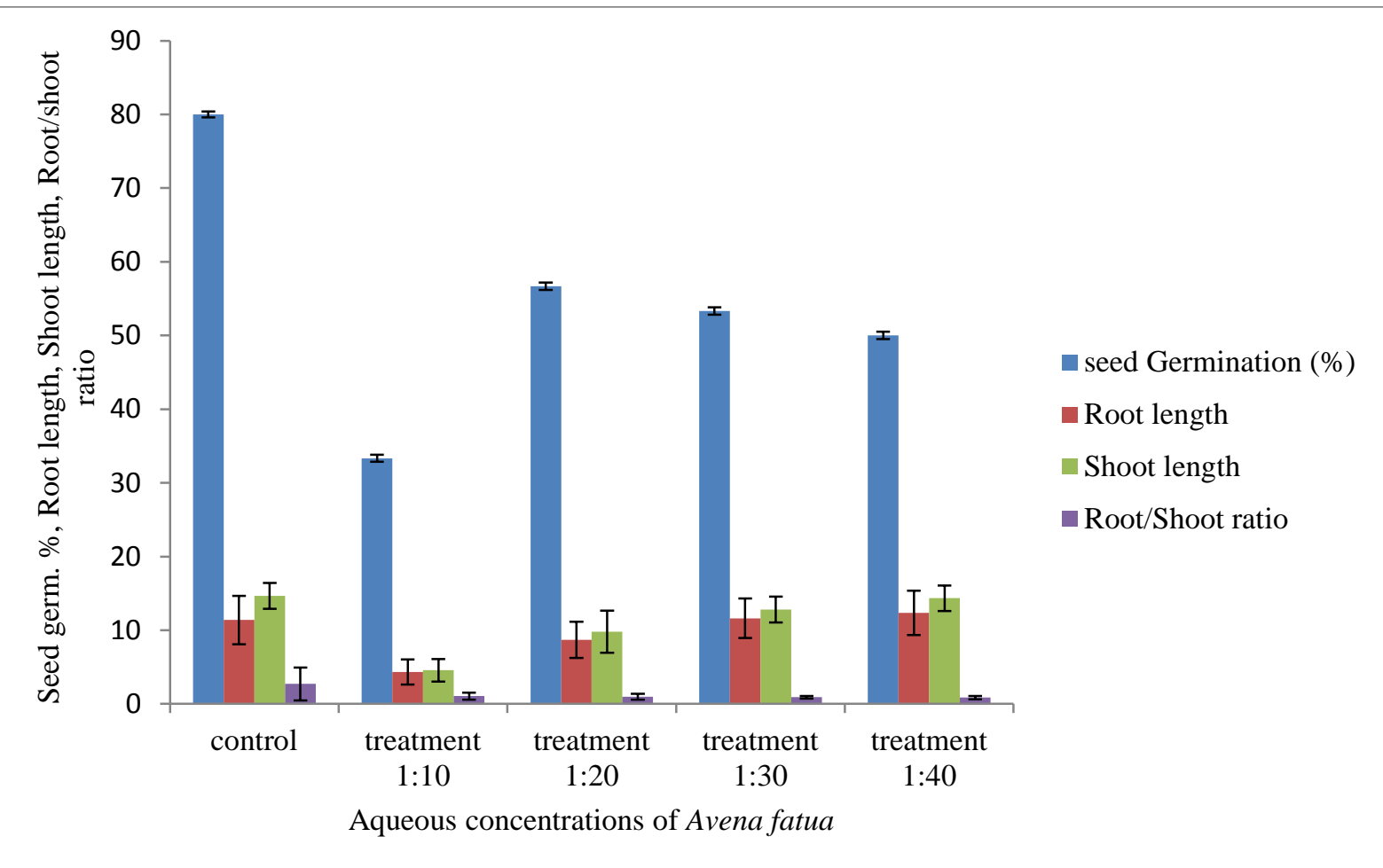

Fig.1: Depicting effects of aqueous extracts of Avena fatua on seed germination \%, shoot length, root length and root/shoot ratio

\section{Conclusion:}

In conclusion, the allelochemicals present in the aqueous extracts of Avena fatua strongly inhibited the seed germination and seedling growth parameters such as root length, shoot length and root/shoot ratio of the winter wheat variety GW-273. Further studies are necessary to encompass the urgent need for devising and implementing a management strategy for the losses caused by the dominant weed specie Avena fatua on wheat.

\section{References:}

[1]. Anderson, R. (2003). An ecological approach to strengthen weed management in the semiarid Great Plains. Advances in Agronomy. 80: 33-62.

[2]. Anderson, W.P. (1987). Weed science as it relates to crop production. In: CRC Handbook of plant science in Agriculture. Vol. II. (Ed. B. R. Christie). CRC. Press Inc. Boca Raton. Florida. 100-113.

[3]. Bhatia, R.K., Gill, H.S. and Mehra, S.P. (1982). Allelopathic potential of some weeds on wheat. Indian Journal Weed science.14 (2): $108-114$.

[4]. Evenari, M. (1980). The history of germination research and the lesson it contains for today. Israel Bot. 29: 4.

[5]. Ghafoor, A. and Sadiq, M. (1991). Critical period of weed crop competition in winter wheat. Pak. J. Agric. Res. 12(1): 13-23.

[6]. Guenzi, W.D. and McCalla, T.M. (1962). Inhibition of germination and seedling development by crop residues. Soil Sci.Soc.Am. Proc.26: 456-458.

[7]. Guenzi, W.D. and McCalla, T.M. (1966). Phenolic acids in oat, wheat, sorghum and corn residues and their phytotoxicity. Agron. J. 58: 303-304.

[8]. Hassan, G. and Marwat, K.B. (2001). Integrated weed management in Agricultural crops. Paper presented in National Workshop on Technologies for Sustainable Agriculture. NIAB, Faisalabad, Pakistan. 24-26.

[9]. Howell, R.W. (1960). Physiology of soybean. Adv. Agron. 12: 265-310.

[10]. Kaul, M.I.H. and Mangal, P.D. (1985b). Biological equipment of crown beard. II. Seed inhibition, germination, seedling survival and transplantation. Biologica 1 (2): 208-213.

[11]. Kaul, M.I.H. and Mangal, P.D. (1985b). Biological equipment of crown beard. II. Seed inhibition, germination, seedling survival and transplantation. Biologica 1 (2): 208-213.

[12]. Murray, R.D.H., Méndez, J. and Brown, S.A. (1982). The natural coumarins: Occurrence, chemistry and biochemistry. Wiley, Chichester.

[13]. Musik, T.A. (1970). Weed biology and control. McGraw Hill Book Co. New York. 273.

[14]. Nielsen, K., Cuddy, T. and Woods, W. (1960). The influence of the extracts of some crops and soil residues on germination and growth. Can. J. Plant Sci. 40: 188-197.

[15]. Putnam, A.R. (1987). Preface to special Allelopathy Edition. Plant and Soil. 98:3.

[16]. Retta, A., Vanderlip, R.L., Higgins, R.A., Moshier, L.J. and Feyerherm, A.M. (1991). Suitability of corn growth models for incorporation of weed and insect tresses. Agron J. 83:757-765.

[17]. Rice, E.L. (1984). Allelopathy, 2nd edition. Academic Press, Orlando.

[18]. Siddiqui, S., Bhardwaj, S., Saeed, S.K. and Meghvanshi, M.K. (2009). Allelopathic Effect of Different Concentration of Water Extract of Prosopsis Juliflora Leaf on Seed Germination and Radicle Length of Wheat (Triticum aestivum Var- Lok-1). American Eurasian. J.Sci. Res. 4 (2): 81-84. 
[19]. Schumacher, W.J., Thill, D.C. and Lee, G.A. (1982). The allelopathic potential of wild oats (Avena fatua L.) on spring wheat growth. North. Am. Symp. Allelopathy. . Urbana. Champaign. Illinois, (Abstr.): 14-17.

[20]. Schumacher, W.J., Thill, D.C. and Lee, G.A. (1983). Allelopathic potential of wild oat (Avena fatua) on spring wheat (Triticum aestivum) growth. J. Chem. Ecol. 9:1235-1245.

[21]. Tanveer, A.R.A. and Ayub, M. (2001). Competition effect of Chenopodium album L. for potassium and grain yield in wheat (Triticum aestivum L.) Sultan Qaboos Univ. J. Sc. Res. Agri. Sc. 6 (1-2): 11-14.

[22]. Zenab, R., Shahid, S.S. and Imran, A. (2001). Allelopathic potential of Anagallis arvensis L.: A cosmopolitan Weed. Pak. J. Biol. Sci. 4 (4): 446-450. 